\title{
Components of metabolic syndrome in the first trimester of pregnancy as predictors of adverse perinatal outcome
}

\author{
Michał Migda ${ }^{1}$, Marian S. Migda ${ }^{2}$, Bartosz Migda ${ }^{3}$, Patrycja Krzyżanowska ${ }^{4}$, \\ Ewa Wender-Ożegowska ${ }^{5}$ \\ ${ }^{1}$ Clinical Unit of Obstetrics, Women's Disease and Gynecological Oncology, United District Hospital, \\ Collegium Medicum University of Nicolaus Copernicus in Torun, Poland \\ ${ }^{2}$ Civis Vita Centrum Medyczne in Torun, Poland \\ ${ }^{3}$ Department of Diagnostic Imaging, Second Faculty of Medicine with the English Division and the Physiotherapy Division, \\ Medical University of Warsaw, Poland \\ ${ }^{4}$ Department of Paediatric Gastroenterology and Metabolic Diseases, Poznan University of Medical Sciences, Poland \\ ${ }^{5}$ Department of Obstetrics and Women's Diseases, University of Medical Sciences, Poznan, Poland
}

\begin{abstract}
Objectives: It is the prospective observational study aimed at early prediction of pregnancy complications in women with symptoms of MS.

Material and methods: 124 Caucasian women in singleton pregnancies $11^{\text {th }}$ to the $13^{\text {th }}$ wks 6 days of gestation with MS criteria compared to 30 healthy controls. Perinatal maternal and fetal results were analyzed.

Results: Increased in the MS group were: age (32.9 y vs. 28.6 y; $p=0,00)$, weight 11 to $13+6$ weeks of gestation (79.0 kg vs. $59.7 \mathrm{~kg} ; \mathrm{p}=0.00), \mathrm{BMI}\left(29 \mathrm{~kg} / \mathrm{m}^{2}\right.$ vs. $\left.21.6 \mathrm{~kg} / \mathrm{m}^{2} ; \mathrm{p}=0.00\right)$, waist-hip ratio (WHR) (0.9 vs. 0.8; $\left.\mathrm{p}=0.00\right)$. Maternal serum parameters were higher in the MS group: LDL-cholesterol (124.1 vs. $109.6 \mathrm{mg} / \mathrm{dL} ; \mathrm{p}=0.02), \mathrm{t}-\mathrm{PA}(2556.8 \mathrm{vs} .1949 .5 \mathrm{pg} / \mathrm{mL} ; \mathrm{p}<0.00)$,

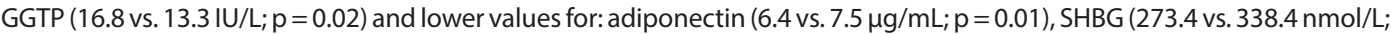
$\mathrm{p}=0.001$ ). MS group neonates higher body weight (3594.4 vs. $3312.2 \mathrm{~g} ; \mathrm{p}=0.01$ ), significantly frequent macrosomic neonates (> 4000 g) (20.9\% vs. $6.6 \% ; p=0.042)$, GDM (12\% vs. $0 ; p=0.019)$.

Conclusions: Higher E-selectin serum concentration, GGTP and lower SHBG in the first trimester are additionally to fasting maternal glucose, higher BMI and maternal age predictive for GDM. Higher E-selectin, fasting glucose, increased BMI and lower adiponectin serum concentration in the first trimester are significant predictors of fetal macrosomia. Maternal $\mathrm{BMI}>24.5 \mathrm{~kg} / \mathrm{m}^{2}$ is the best predictor of increased risk of fetal macrosomia and gestational diabetes mellitus.
\end{abstract}

Key words: metabolic syndrome, adiponectin, gestational diabetes mellitus, macrosomy, E-selectin, body mass index (BMI)

\section{INTRODUCTION}

In 2005, the World Health Organization (WHO) estimated that at least 400 million adults were obese (defined as having a body mass index $[\mathrm{BMI}]>30 \mathrm{~kg} / \mathrm{m}^{2}$ ), and that this figure is projected to rise to over 700 million by 2015 [1]. Obesity among pregnant women is highly prevalent and is associated with an increased risk of adverse outcomes for mother and infant [2]. Epidemiological studies in Poland confirm this global phenomenon of a growing number of obese adults. The largest studies show that $28-29 \%$ women are overweight (BMI $25.0-29.9 \mathrm{~kg} / \mathrm{m}^{2}$ ), and $19-22 \%$ are obese $\left(\mathrm{BMI}>30 \mathrm{~kg} / \mathrm{m}^{2}\right)$ [3-4]. Increased $\mathrm{BMl}$ is a major determinant of pregnancy outcome, and maternal obesity is associated with increased risk of the majority of pregnancy complications, including maternal complications such as gestational diabetes mellitus (GDM), gestational hypertension $(\mathrm{GH})$, preeclampsia (PE), venous thromboembolism (VT), increased cesarean delivery rate. Furthermore, fetal complications are more likely, including small for gestational age (SGA), intrauterine growth restriction (IUGR), macroso- 
mia and stillbirth [2, 4]. Maternal metabolic disturbances, such as increased blood pressure, decreased insulin sensitivity and elevated plasma lipids are accelerated during pregnancy, secondary to the increased metabolic needs of the placenta and fetus [5-6]. Levels of serum adiponectin, an adipocytokine released from adipose tissue, are inversely correlated with insulin resistance, and its reduced concentration is apparent from the first trimester of pregnancy. It is possible, that serum adiponectin may be a biomarker of metabolic derangement observed in obesity and GDM [7]. Additionally, fat tissue is responsible for the chronic inflammatory response, which in pregnancy can lead to endothelial dysfunction, a potential cause of preeclampsia [8]. The expression of the adhesion molecule E-selectin is tightly regulated by the inflammatory response: soluble forms are released into the circulation and may indicate endothelial dysfunction. Consequently, it is considered to be a potential marker of preeclampsia [8].

The aim of this study was to evaluate metabolic syndrome (MS) exponents in pregnant women in the first trimester of gestation to find and confirm any correlation with perinatal complications.

\section{MATERIAL AND METHODS}

This was a prospective observational study aimed at the early prediction of pregnancy complications in women with symptoms of MS. The study was conducted between 2011 and 2013. During routine visits in pregnancy, held between the $11^{\text {th }}$ to the $13^{\text {th }}$ weeks and 6 days of gestation, we recorded maternal characteristics, anthropometric data, and medical history and we performed combined screening for aneuploidies. The population comprised 127 Caucasian women in singleton pregnancies who fulfilled criteria for MS. These criteria included the presence of any 3 of 5 risk factors: population-specific elevated waist circumference; elevated triglycerides (drug treatment for elevated triglycerides is an alternate indicator) $\geq 150 \mathrm{mg} / \mathrm{dL}$; reduced high density lipoprotein cholesterol (HDL-C) (drug treatment for reduced $\mathrm{HDL}-\mathrm{C}$ is an alternate indicator) $<40 \mathrm{mg} / \mathrm{dL}$ $(1.0 \mathrm{mmol} / \mathrm{L})$ in males and $<50 \mathrm{mg} / \mathrm{dL}(1.3 \mathrm{mmol} / \mathrm{L})$ in females; elevated blood pressure (antihypertensive drug treatment in a patient with a history of hypertension is an alternate indicator) systolic $\geq 130$ and/or diastolic $\geq 85 \mathrm{~mm} \mathrm{Hg}$; and, elevated fasting glucose (drug treatment of elevated glucose is an alternate indicator) $\geq 100 \mathrm{mg} / \mathrm{dL}$ [9]. The control group comprised 30 women with health pregnancies. For the final analysis, we included 124 women and 30 controls who completed informed, written consent.

At designated pregnancy visits (11-13 \pm 6 weeks) blood samples were taken after overnight fasting and transported to the certificated Vitalabo Labolatory Diagnostics in Torun the same day following biological specimen regulations in cooling conditions $2-8^{\circ} \mathrm{C}$. Analysis of delivered material was performed on the same day. HDL-C, triglicerides (TG), total cholesterol $(\mathrm{CH})$ and additional parameters including: tissue plasminogen activator (t-PA), sex-hormone binding globulin (SHBG) and gamma glutamyl transpeptidase (GGTP) were measured as biomarkers for MS (Roche Diagnostics reagents on a Cobas c501 analyzer). The following formula was used to calculate the level of low density lipoprotein (LDL) cholesterol: LDL cholesterol = total cholesterol $-\mathrm{HDL}$ cholesterol $-(\mathrm{TG} / 5)$. Thestandard oral glucose tolerance test (OGTT) was performed in the MS group in the first trimester and if GDM was excluded this test was repeated in the second trimester of pregnancy with $75 \mathrm{~g}$ of glucose at 24-28 weeks of pregnancy, according to Polish Gynecology Society Recommendations [10]. In the control group, the OGTT was performed in the second trimester, between the $24-28^{\text {th }}$ week. Gestational hypertension was noted if systolic blood pressure was above 140 or diastolic was above $90 \mathrm{~mm} \mathrm{Hg}$, and the patient had preeclampsia with the presence of proteinuria above $300 \mathrm{mg} / \mathrm{d}$. In all participants, at the same time, blood was also drawn for assessment of serum adiponectin and E-selectin concentrations. Blood samples were centrifuged, aliquoted and stored at $-80^{\circ} \mathrm{C}$ until assayed in the Department of Pediatric Gastroenterology and Metabolic Diseases Clinic, University of Medical Science in Poznan, using commercially available ELISA kits (R\&D Systems, Minneapolis, USA). Anthropometric measurements (height, weight, and waist/hip circumference) and blood pressure measurements were performed the onset of the study.

Large-for-gestational age (LGA) was defined as birth weight greater than the $90^{\text {th }}$ percentile using age- and sex-specific regional growth charts. Small-for-gestational (SGA) was defined as birth weight smaller than $10^{\text {th }}$ centile on the same charts.

The study protocol was approved by University of Medical Science in Poznań Ethics Committee no 284/11.

\section{Statistical analysis}

Statistical analysis of the obtained data was performed using the original statistical package modules of Statistica 10 (Statsoft Inc.). Variable distribution was assessed with the Shapiro-Wilk test. Comparison of unpaired quantitative variables was performed with the Student t-test or Cochrane-Cox test, depending on the distribution of data. In the case of non-normally distributed data, comparisons were made using the Mann-Whitney $U$ test and the Chi-squared test was used for the comparison of categorical variables with Yates's correction for continuity due to the low case count $<5$. Statistical significance was defined as $p<0.05$. The detection rate of adverse outcomes in pregnancy, in addition to other analyses, was determined by the receiver operating curve $(\mathrm{ROC})$ analysis. 


\section{RESULTS}

Maternal anthropometric characteristics in the MS and control groups are compared in Table 1. The following variables were significantly different between the MS and the control group: patient age (32.9 years vs. 28.6 years; $p=0.00$ ), weight in the 11th to 13 th ( \pm 6 days) weeks of gestation (79.0 kg vs. $59.7 \mathrm{~kg} ; \mathrm{p}=0.00), \mathrm{BMI}\left(29 \mathrm{~kg} / \mathrm{m}^{2}\right.$ vs. $21.6 \mathrm{~kg} / \mathrm{m}^{2}$; $\mathrm{p}=0.00)$, and waist-hip ratio (WHR) (0.9 vs. $0.8 ; \mathrm{p}=0.00)$. Other variables, measured in the first trimester of pregnancy, including maternal weight gain during pregnancy, height, arterial blood pressure, both systolic and diastolic, showed no significant difference between the groups.

The maternal serum parameters measured in the first trimester of pregnancy in patients with MS and in the control group are compared in Table 2. The following variables are significantly higher in the MS group: LDL-cholesterol (124.1 vs. $109.6 \mathrm{mg} / \mathrm{dL} ; \mathrm{p}=0.02)$, t-PA (2556.8 vs. $1949.5 \mathrm{pg} / \mathrm{mL}$; $\mathrm{p}<0.00)$, and GGTP (16.8 vs. $13.3 \mathrm{IU} / \mathrm{L} ; \mathrm{p}=0.02)$. Statistical analysis showed significantly lower values of the following parameters in MS patients compared to the control group: adiponectin (6.4 vs. $7.5 \mu \mathrm{g} / \mathrm{mL} ; \mathrm{p}=0.01)$ and SHBG (273.4 vs. $338.4 \mathrm{nmol} / \mathrm{L}$; $\mathrm{p}=0.001)$. Levels of E-selectin and fasting glucose were not significantly different between the groups.

Prospective analysis of maternal and fetal pregnancy outcomes in cases with MS and in controls is shown in
Table 3. MS patients delivered neonates of significantly higher body weight (3594.4 g vs. $3312.2 \mathrm{~g} ; \mathrm{p}=0.01$ ). The number of macrosomic neonates $(>4000 \mathrm{~g}$ ) was also higher in the MS group ( $20.9 \%$ vs. $6.6 \% ; p=0.042$ ) as well as the incidence of GDM ( $12 \%$ vs. $0 \% ; p=0.019)$. The number of caesarean sections, LGA- and SGA- newborns, cases with gestational hypertension, $\mathrm{PE}$ and preterm delivery showed no differences between the MS group and control group. No patients with VT were observed in either group.

First trimester maternal parameters in women who developed GDM and those who did not are presented in Table 4. GDM patients were significantly older, presented in the first trimester with a significantly higher BMI, had higher concentration of fasting glucose, GGTP and E-selectin, and had a lower concentration of SHBG compared to patients without GDM. Serum adiponectin levels did not differ between the groups.

The maternal characteristics and biochemical profile of women who delivered macrosomic babies are presented in Table 5 . In the pregnancies with macrosomia $(n=28)$ compared to those who delivered eutrophic neonates, the following variables were higher: BMI ( 28.0 vs. $\left.22.0 \mathrm{~kg} / \mathrm{m}^{2} ; \mathrm{p}<0.001\right)$, maternal weight in the first trimester of pregnancy $(77.9 \mathrm{vs} .60 .8 \mathrm{~kg}$; $\mathrm{p}<0.001)$, fasting glucose (87.2 vs. $82.1 \mathrm{mg} / \mathrm{dL} ; \mathrm{p}<0.042)$ and E-selectin concentration ( 32.1 vs. $24.5 \mathrm{ng} / \mathrm{mL} ; \mathrm{p}=0.01$ ). Table 1. Maternal anthropometric characteristics of the MS and of the control group

\begin{tabular}{|c|c|c|c|c|c|c|c|c|c|}
\hline \multirow{2}{*}{ Variable } & \multicolumn{4}{|c|}{$\begin{array}{c}\text { MS group } \\
(n=124)\end{array}$} & \multicolumn{4}{|c|}{$\begin{array}{l}\text { Control group } \\
\qquad(n=30)\end{array}$} & \multirow[t]{2}{*}{$\mathbf{P}$} \\
\hline & $\overline{\mathbf{x}}$ & MIN & MAX & SD & $\overline{\mathbf{x}}$ & MIN & MAX & SD & \\
\hline Age (years) & 32.9 & 20.0 & 43.0 & 5.0 & 28.6 & 22.0 & 40.0 & 4.0 & $0.00^{* *}$ \\
\hline I trimester weight [kg] & 79.0 & 52.0 & 126.0 & 11.9 & 59.7 & 46.0 & 76.0 & 6.7 & $0.00^{*}$ \\
\hline I trimester BMI $\left[\mathrm{kg} / \mathrm{m}^{2}\right]$ & 29.0 & 19.2 & 47.0 & 4.2 & 21.6 & 16.5 & 24.5 & 2.4 & $0.00^{* *}$ \\
\hline WHR & 0.9 & 0.7 & 1.0 & 0.1 & 0.8 & 0.7 & 1.0 & 0.1 & $0.00 * *$ \\
\hline
\end{tabular}

*Cochrane-Cox test; ${ }^{* *}$ Mann-Whitney test; $\bar{x}$ - median; SD — standard deviation

Table 2. Maternal serum adiponectin, E-selectin and metabolic syndrome markers in the MS and in the control group

\begin{tabular}{|c|c|c|c|c|c|c|c|c|c|}
\hline \multirow{2}{*}{ Variable } & \multicolumn{4}{|c|}{$\begin{array}{l}\text { MS group } \\
(n=124)\end{array}$} & \multicolumn{4}{|c|}{$\begin{array}{l}\text { Control group } \\
\qquad(n=30)\end{array}$} & \multirow{2}{*}{$\mathbf{p}$} \\
\hline & $\overline{\mathbf{x}}$ & MIN & MAX & SD & $\overline{\mathbf{x}}$ & MIN & MAX & SD & \\
\hline LDL cholesterol [mg/dL] & 124.1 & 70.5 & 280.5 & 30.2 & 109.6 & 76.2 & 162.7 & 23.4 & $0.015 *$ \\
\hline Fasting glucose $[\mathrm{mg} / \mathrm{dL}]$ & 85.6 & 70.1 & 142.9 & 8.2 & 82.4 & 66.2 & 97.6 & 6.2 & $0.05^{* *}$ \\
\hline $\mathrm{t}-\mathrm{PA}[\mathrm{pg} / \mathrm{ml}]$ & 2556.8 & 353.5 & 10000.0 & 1148.4 & 1949.5 & 935.5 & 6751.3 & 1027.6 & $<0.00 * *$ \\
\hline GGTP [IU/I] & 16.8 & 5.0 & 87.0 & 12.8 & 13.3 & 5.6 & 76.0 & 12.3 & $0.02 * *$ \\
\hline Adiponectin $[\mu \mathrm{g} / \mathrm{mL}]$ & 6.4 & 1.8 & 26.3 & 3.4 & 7.5 & 2.4 & 12.6 & 2.7 & $0.01^{* *}$ \\
\hline E-selectin $[\mathrm{ng} / \mathrm{mL}]$ & 28.9 & 11.0 & 59.0 & 11.2 & 24.7 & 12.0 & 41.0 & 8.3 & $0.09 * *$ \\
\hline $\mathrm{SHGB}[\mathrm{nmol} / \mathrm{L}]$ & 273.4 & 68.3 & 706.1 & 97.4 & 338.4 & 168.0 & 521.3 & 92.0 & $0.001 *$ \\
\hline
\end{tabular}

*t-Student test; ${ }^{* *}$ Mann-Whitney test; $\bar{x}$ — median; SD — standard deviation 
Table 3. Maternal and fetal outcome in MS and in the control group

\begin{tabular}{|c|c|c|c|c|c|}
\hline Parameters & \multicolumn{2}{|c|}{$\begin{array}{l}\text { MS group } \\
(n=124)\end{array}$} & \multicolumn{2}{|c|}{$\begin{array}{l}\text { Control group } \\
\quad(n=30)\end{array}$} & $\mathbf{p}$ \\
\hline \multirow{4}{*}{ Neonatal weight [g] } & $\bar{x}$ & 3594.4 & $\bar{x}$ & 3312.2 & \multirow{4}{*}{$0.01 * * *$} \\
\hline & $\min$ & 560 & $\min$ & 1460.0 & \\
\hline & $\max$ & 5130 & $\max$ & 4450.0 & \\
\hline & SD & 637.0 & SD & 544.5 & \\
\hline Cesarean section ( $\mathrm{N}, \%)$ & \multicolumn{2}{|c|}{$43(34.7)$} & \multicolumn{2}{|c|}{$8(26.7)$} & $0.403^{*}$ \\
\hline Preterm delivery < 37 wks $(\mathrm{N}, \%)$ & \multicolumn{2}{|c|}{$4(3.2)$} & \multicolumn{2}{|c|}{$1(3.3)$} & $0.582^{* *}$ \\
\hline Neonatal weight $>4000 \mathrm{~g}(\mathrm{~N}, \%)$ & \multicolumn{2}{|c|}{$26(20.9)$} & \multicolumn{2}{|c|}{$2(6.6)$} & $0.0422 *$ \\
\hline LGA > 90 percentile $(\mathrm{N}, \%)$ & \multicolumn{2}{|c|}{$16(12.9)$} & \multicolumn{2}{|c|}{$2(6.6)$} & $0.524^{* *}$ \\
\hline SGA < 10 percentile $(N, \%)$ & \multicolumn{2}{|c|}{$5(4.0)$} & \multicolumn{2}{|c|}{$1(3.3)$} & $0.747^{* *}$ \\
\hline GDM (N, \%) & \multicolumn{2}{|c|}{$12(9.6)$} & \multicolumn{2}{|c|}{0} & $0.019 *$ \\
\hline Gestational hypertension (N, \%) & \multicolumn{2}{|c|}{$7(5.6)$} & \multicolumn{2}{|c|}{$1(3.3)$} & $0.957^{* *}$ \\
\hline $\mathrm{PE}(\mathrm{N}, \%)$ & \multicolumn{2}{|c|}{$1(0.8)$} & \multicolumn{2}{|c|}{0} & $0.439^{* *}$ \\
\hline
\end{tabular}

${ }^{*} \mathrm{X}^{2}$ test; ${ }^{* *} \mathrm{X}^{2}$ test with Yates correction; ${ }^{* *}$ Mann-Whitney test; $\overline{\mathrm{x}}$ - mean; $\mathrm{SD}$ - standard deviation; $\mathrm{N}$ - number of cases

Table 4. Maternal characteristics and biochemical parameters in the first trimester in patients who developed GDM

\begin{tabular}{|c|c|c|c|c|c|c|c|c|c|}
\hline \multirow{2}{*}{ Variable } & \multicolumn{4}{|c|}{$\begin{array}{l}\text { GDM group } \\
(n=19)\end{array}$} & \multicolumn{4}{|c|}{$\begin{array}{l}\text { Non-GDM group } \\
\quad(n=135)\end{array}$} & \multirow{2}{*}{$\mathbf{p}^{*}$} \\
\hline & $\overline{\mathbf{x}}$ & MIN & MAX & SD & $\overline{\mathbf{x}}$ & MIN & MAX & SD & \\
\hline Age (years) & 34.7 & 30.0 & 43.0 & 3.9 & 28.7 & 20.0 & 40.0 & 4.3 & $<0.01$ \\
\hline I trimester BMI [kg/m²] & 31.6 & 24.2 & 47.0 & 7.4 & 21.8 & 16.5 & 30.8 & 2.9 & $<0.00$ \\
\hline Fasting glucose [mg/dL] & 104.2 & 95.2 & 142.9 & 15.1 & 82.4 & 66.2 & 92.1 & 5.7 & $<0.00$ \\
\hline Adiponectin $[\mu \mathrm{g} / \mathrm{mL}]$ & 6.0 & 3.5 & 11.3 & 2.5 & 8.3 & 2.4 & 26.3 & 4.3 & 0.07 \\
\hline GGTP [IU/I] & 24.7 & 7.3 & 87.0 & 22.6 & 12.9 & 5.0 & 76.0 & 12.4 & $<0.03$ \\
\hline E-selectin [ng/mL] & 32.3 & 16.0 & 59.0 & 10.5 & 24.7 & 11.0 & 41.0 & 8.3 & $<0.04$ \\
\hline SHGB [nmol/L] & 249.0 & 68.3 & 396.8 & 100.3 & 338.4 & 168.0 & 521.3 & 92.0 & $<0.02$ \\
\hline
\end{tabular}

*Mann-Whitney test; $\bar{x}$ - mean; SD — standard deviation

Table 5. Maternal characterstics and biochemical analysis in the first trimester of pregnancy that delivered macrosomic neonates

\begin{tabular}{|c|c|c|c|c|c|c|c|c|c|}
\hline \multirow{2}{*}{ Variable } & \multicolumn{4}{|c|}{$\begin{array}{c}\text { Macrosomia }(>4000 \mathrm{~g}) \\
(\mathrm{n}=28)\end{array}$} & \multicolumn{4}{|c|}{$\begin{array}{l}\text { Non-macrosomia } \\
\qquad(n=126)\end{array}$} & \multirow[t]{2}{*}{$\mathbf{p}^{*}$} \\
\hline & $\overline{\mathbf{x}}$ & MIN & MAX & SD & $\overline{\mathbf{x}}$ & MIN & MAX & SD & \\
\hline Maternal weight (11-14 wks) [kg] & 77.9 & 58.0 & 126.0 & 14.7 & 60.8 & 46.0 & 86.0 & 8.42 & $<0.001$ \\
\hline Maternal BMI $\left[\mathrm{kg} / \mathrm{m}^{2}\right]$ & 28.0 & 20.5 & 47 & 5.4 & 22.0 & 16.5 & 30.5 & 2.9 & $<0.001$ \\
\hline Fasting glucose $[\mathrm{mg} / \mathrm{dL}]$ & 87.2 & 70.1 & 142.9 & 12.9 & 82.1 & 66.2 & 97.6 & 6.3 & $<0.042$ \\
\hline Adiponectin $[\mu \mathrm{g} / \mathrm{mL}]$ & 5.6 & 3.2 & 7.7 & 1.5 & 9.1 & 4.7 & 26.3 & 3.9 & $<0.001$ \\
\hline E-selectin [ng/mL] & 32.1 & 12.0 & 59.0 & 10.8 & 24.5 & 11.0 & 43.0 & 8.3 & 0.01 \\
\hline
\end{tabular}

*Mann-Whitney test; $\bar{x}$ - mean; SD — standard deviation

Adiponectin serum levels were significantly lower in the macrosomic group compared to the eutrophic group (5.6 vs. $9.1 \mu \mathrm{g} / \mathrm{mL} ; \mathrm{p}<0.001)$.

The main aim of this study was to identify any parameters that may have the best predictive value for an adverse preg- nancy outcome. The ROC for all parameters that had an area under the curve (AUC) above 0.7 , are presented in Table 6 . The best predictive value for adverse outcomes in pregnancy was associated with GDM, GH, LGA and macrosomia, and BMI $>24.5 \mathrm{~kg} / \mathrm{m}^{2}(0.943,0.925,0.927$ and 0.911) (Tab. 7). 
Table 6. AUROC values for measured paremeters in pregnancy complication prediction

\begin{tabular}{|l|c|c|c|c|c|c|}
\hline \multirow{2}{*}{ AUC } & \multicolumn{7}{|c|}{ Pregnancy complication } \\
\cline { 2 - 7 } & GDM & GH & LGA & Macrosomia & SGA & Cesarean section \\
\hline Waist circumference & 0.738 & - & - & - & 0.836 & 0.706 \\
\hline Body weight in I trimester & 0.925 & 0.942 & 0.914 & 0.894 & 0.863 & 0.773 \\
\hline Weight gain & - & - & - & 0.739 & - & - \\
\hline RR systolic & - & 0.777 & - & - & - & - \\
\hline WHR & - & - & 0.713 & - & - & 0.732 \\
\hline Age & 0.858 & - & - & - & 0.790 & - \\
\hline Adiponectin & - & - & - & 0.875 & - & - \\
\hline E-selectin & 0.708 & - & - & - & - & - \\
\hline Total cholesterol & -- & 0.798 & - & - & - & - \\
\hline SHBG & 0.736 & - & - & - & - & - \\
\hline Fasting glucose & 0.894 & - & - & - & - & - \\
\hline t-PA & - & 0.742 & - & - & - & - \\
\hline
\end{tabular}

Table 7. Receiver operator curve BMI values summary for pregnancy adverse outcomes

\begin{tabular}{|l|c|c|c|c|}
\hline \multirow{2}{*}{ Pregnancy complications } & \multicolumn{3}{|c|}{ BMI } \\
\cline { 2 - 5 } & AUC & Sensitivity & Specificity & Cut-off \\
\hline GDM & 0.943 & 0.917 & 0.833 & 24.5 \\
\hline GH & 0.925 & 0.875 & 0.800 & 24.5 \\
\hline LGA & 0.927 & 0.880 & 0.933 & 25.5 \\
\hline Macrosomia & 0.911 & 0.833 & 0.933 & 25.5 \\
\hline
\end{tabular}

\section{DISCUSSION}

MS is a cluster of interrelated metabolic factors such as insulin resistance, hyperinsulinemia, abdominal obesity, impaired glucose tolerance, dyslipidemia, and hypertension, in the context of a proinflammatory and prothrombotic state [11]. Our results confirm that patients with MS have significantly increased BMI, and significantly increased incidence of GDM compared to patients without MS. Our data did not confirm observations regarding other pregnancy adverse outcomes as published in the research literature. For instance, Beaten et al. suggested, that obese and overweight women had a consistent increase not only in the frequency of GDM, but also PE and eclampsia in comparison to women with a BMI of less than $20 \mathrm{~kg} / \mathrm{m}^{2}$ [12]. Sebire et al. also confirmed an increased risk of GDM, PE, LGA and caesarean sections, but surprisingly decreased risk of preterm delivery, in group of pregnant women with a BMI > 25kg/ $\mathrm{m}^{2}$ [13].

There are studies suggesting that there is an increased risk of preterm delivery in MS patients associated with low levels of serum adiponectin [14]. In our study, decreased serum adiponectin in the MS group was observed, but a small number of cases with preterm delivery did not confirm previous study findings. Another adverse pregnancy outcome we have observed in our study was GDM. According to Wójcikowski et al., the prevalence of GDM in Polish population is $2-3.8 \%$, depending on the region [15]. However, following publication of this study, new criteria for GDM were established and accordingly the incidence of GDM in the Polish population may be different. In our study, the prevalence of GDM was $9.6 \%$ in women with a BMI $>25 \mathrm{~kg} / \mathrm{m}^{2}$. The BMI cut-off value, above which the risk of GDM was significantly increased, was $24.5 \mathrm{~kg} / \mathrm{m}^{2}$. Ogonowski et al. suggested that the risk of GDM is significantly higher in patients with a BMI $>22.85 \mathrm{~kg} / \mathrm{m}^{2}$. This is the only paper published that suggests such low cut-off of BMI as a risk factor for GDM [16]. Lacroix et al. published data showing significantly decreased serum adiponectin levels in the first trimester of pregnancy in patients who later developed GDM [17]. Our data confirmed this observation. We also observed in the MS group of patients an increased prevalence of GDM and lower serum adiponectin levels in the first trimester of pregnancy, in comparison to patients without MS. The likely mechanism underlying a lower adiponectin serum concentration and the presence of GDM is increased insulin resistance and glucose intolerance. Similar observations have been noted by Nanda et al., who researched pregnant women delivering macrosomic neonates [7]. 
In the GDM group, we also confirmed the possible role of SHBG as a marker of liver response to insulin, as well as of insulin resistance, manifested by increased GGTP levels. This finding is consistent with data collected by Kavanagh et al., who also observed lower SHBG in obese women [18]. In our study, we also noticed a significantly decreased SHBG concentration in patients with GDM in comparison to the non-GDM group.

What is also important, recent reports show, is that undiagnosed GDM increases the risk of certain maternal and fetal complications, including pregnancy-induced hypertension, $P E$, macrosomy, stillbirth, miscarriage and fetal anomalies, especially in the central nervous system [19-21]. It has been reported that t-PA has a mitogenic role in smooth muscle cells, suggesting that its overproduction may contribute to vascular damage, although it may also favour atherogenesis. Hypertriglyceridemia has been observed in patients with $\mathrm{PE}$, which may compromise endothelial cell function and thus may favour thrombosis and atherosclerosis [22]. Belo et al. noticed that increased serum t-PA levels were present in the third trimester of pregnancy in women with PE [22]. In our study, we also observed higher $t-P A$ levels in the first trimester in the MS group, but due to small number of PE cases we could not confirm its predictive role for this complication.

Our results reinforce the observation of fetal excessive weight gain in obese patients. We found a significantly increased number of neonates weighing more than $4000 \mathrm{~g}$ in the MS group in comparison to the group with MS. The BMI cut-off value for LGA and macrosomia was $24.5 \mathrm{~kg} / \mathrm{m}^{2}$. One of the parameters that differed between these two study groups was the concentration of LDL-cholesterol. The pathogenesis of that phenomenon is uncertain, however Freinkel et al. suggested that excessive fetal weight may be caused by increased transplacental lipid transport related to maternal hyperlipidemia [23].

In our study, due to the small number of patients with PE, we were not able to evaluate the role of E-selectin in the pathogenesis of $\mathrm{PE}$. However, recent data suggest that E-selectin plays important role in the development of PE [8]. We observed an increased serum E- selectin concentration in patients with GDM in comparison to those without GDM. These observations differ from those made by Zawiejska et al., who examined patients with pregestational diabetes mellitus, and reported lower E-selectin levels in this group [24]. In our opinion these opposing results might be related to the longer period of endothelial injury caused by metabolic disturbances in pregestational diabetes mellitus.

\section{CONCLUSIONS}

1. Higher E-selectin serum concentration, GGTP and lower SHBG in the first trimester, in addition to fasting mater- nal glucose, higher BMI and maternal age, are predictive for GDM.

2. Higher E-selectin, fasting glucose, BMI levels, and lower adiponectin serum concentrations in the first trimester are significant predictors of fetal macrosomia.

3. Maternal BMI $>24.5 \mathrm{~kg} / \mathrm{m}^{2}$ is the best predictor of an increased risk of fetal macrosomia and GDM, based on all of the measured parameters.

\section{REFERENCES}

1. World Health Organisation, Global Database on Body Mass Index. 2009.

2. Nelson SM, Matthews P, Poston L. Maternal metabolism and obesity: modifiable determinants of pregnancy outcome. Hum Reprod Update. 2010, 16, 255-275.

3. Berner-Trąbska M, Kowalska-Koprek U, Karowicz-Bilińska A, [et al.]. Wpływ nadwagi lub otyłości u ciężarnych na przebieg ciąży i okresu okołoporodowego z uwzględnieniem stanu urodzeniowego noworodka w oparciu o materiał kliniczny. Ginekol Pol. 2009, 80, 845-850.

4. Gutaj P, Wender-Ozegowska E, Mantaj U, [et al.]. Maternal body mass index and gestational weight gain and their association with perinatal outcome in women with gestational diabetes. Ginekol Pol. 2011, 82, 827-833.

5. Bartha JL, Marin-Segura P, Gonzalez-Gonzalez NL, [et al.]. Ultrasound evaluation of visceral fat and metabolic risk factors during early pregnancy. Obesity. (Silver Spring) 2007, 15, 2233-2239.

6. Catalano PM, Tyzbir ED, Wolfe RR, [et al.]. Longitudinal changes in basal hepatic glucose production and suppression during insulin infusion in normal pregnant women. Am J Obstet Gynecol. 1992, 167, 913-919.

7. Nanda S, Akolekar R, Sarquis R, [et al.]. Maternal serum adiponectin at 11 to 13 weeks of gestation in the prediction of macrosomia. Prenat Diagn. 2011, 31, 479-483.

8. Kim SY, Ryu HM, Yang JH, [et al.]. Maternal serum levels of VCAM-1, ICAM-1 and E-selectin in preeclampsia. J Korean Med Sci. 2004, 19, 688-692.

9. Alberti KG, Eckel RH, Grundy SM, [et al.]. Harmonizing the metabolic syndrome: a joint interim statement of the International Diabetes Federation Task Force on Epidemiology and Prevention; National Heart, Lung, and Blood Institute; American Heart Association; World Heart Federation; International Atherosclerosis Society; and International Association for the Study of Obesity. Circulation. 2009, 120, 1640-1645.

10. Wender-Ozegowska E, Bomba-Opon D, Brazert J, [et al.]. Polish Gynecological Society standards of medical care in management of women with diabetes. Ginekol Pol. 2011, 82, 474-479.

11. Pacholczyk M, Ferenc T, Kowalski J. The metabolic syndrome. Part II: its mechanisms of development and its complications. Postepy Hig Med Dosw. 2008, 62, 543-558.

12. Baeten JM, Bukusi EA, Lambe M. Pregnancy complications and outcomes among overweight and obese nulliparous women. Am J Public Health. 2001, 91, 436-440.

13. Sebire NJ, Jolly M, Harris JP, [et al.]. Maternal obesity and pregnancy outcome: a study of 287,213 pregnancies in London. Int J Obes Relat Metab Disord. 2001, 25, , 1175-1182.

14. Coppola A, Marfella R, Coppola L, [et al.]. Effect of weight loss on coronary circulation and adiponectin levels in obese women. Int $J$ Cardiol. 2009, 134, 414-416.

15. Wojcikowski C, Krolikowska B, Konarzewska J, [et al.]. The prevalence of gestational diabetes mellitus in Polish population. Ginekol Pol. 2002, 73, 811-816.

16. Ogonowski J, Miazgowski T, Kuczynska M, [et al.]. Pregravid body mass index as a predictor of gestational diabetes mellitus. Diabet Med. 2009, 26, 334-338.

17. Lacroix M, Battista MC, Doyon M, [et al.]. Lower adiponectin levels at first trimester of pregnancy are associated with increased insulin resistance and higher risk of developing gestational diabetes mellitus. Diabetes Care. 2013, 36, 1577-1583.

18. Kavanagh K, Espeland MA, Sutton-Tyrrell K, [et al.]. Liver fat and SHBG affect insulin resistance in midlife women: the Study of Women's Health Across the Nation (SWAN). Obesity. (Silver Spring) 2013, 21, 1031-1038.

19. Simmons D. Diabetes and obesity in pregnancy. Best Pract Res Clin Obstet Gynaecol. 2011, 25, 25-36. 
20. Moleda P, Fronczyk A, Jablonska K, [et al.]. Practical implementation of recommendations concerning diagnostic procedures in gestational diabetes. Ginekol Pol. 2015, 86, 132-136.

21. Towpik I, Wender-Ozegowska E. Is diabetes mellitus worth treating? Ginekol Pol. 2014, 85, 220-225.

22. Belo L, Santos-Silva A, Rumley A, [et al.]. Elevated tissue plasminogen activator as a potential marker of endothelial dysfunction in pre-eclampsia: correlation with proteinuria. BJOG. 2002, 109, 1250-1255.
23. Freinkel N. Banting Lecture 1980. Of pregnancy and progeny. Diabetes. 1980, 29, 1023-1035.

24. Zawiejska A, Wender-Ozegowska E, Brazert J. Microvascular complications are associated with low levels of maternal sE-selectin and SVCAM-1 in pregnancy complicated with pregestational diabetes mellitus. Diabetes Res Clin Pract. 2010, 88, 164-170. 